\title{
Antiplatelet antibody predicts platelet desialylation and apoptosis in immune thrombocytopenia
}

Shiying Silvia Zheng,,2 Zohra Ahmadi,, Halina Hoi Laam Leung,, Rose Wong,,2 Feng Yan,,2 José Sail Perdomo"\# and Beng Hock Chong ${ }^{1,2 \#}$

${ }^{1}$ Hematology Research Unit, St. George and Sutherland Clinical School, University of New South Wales, Sydney and ${ }^{2}$ Department of Hematology, St. George Hospital, Kogarah, New South Wales, Australia

\#JSP and BHC contributed equally as co-senior authors.
Correspondence: S. S. Zheng silvia.zheng@health.nsw.gov.au

Received: $\quad$ August 5, 2021.

Accepted: $\quad$ February 18,2021

Prepublished: February 24, 2022.

https://doi.org/10.3324/haematol.2021.279751

@2022 Ferrata Storti Foundation

Published under a CC BY-NC license @() (1) $\Theta$

\begin{abstract}
Immune thrombocytopenia (ITP) is a bleeding disorder caused by dysregulated B- and T- cell functions, which lead to platelet destruction. A well-recognized mechanism of ITP pathogenesis involves anti-platelet and anti-megakaryocyte antibodies recognizing membrane glycoprotein (GP) complexes, mainly GPIb/IX and GPIIb/IIla. In addition to the current view of phagocytosis of the opsonised platelets by splenic and hepatic macrophages via their Fc $\gamma$ receptors, antibodyinduced platelet desialylation and apoptosis have also been reported to contribute to ITP pathogenesis. Nevertheless, the relationship between the specific thrombocytopenic mechanisms and various types of anti-platelet antibodies has not been established. In order to ascertain such association, we used sera from 61 ITP patients and assessed the capacity of anti-platelet antibodies to induce neuraminidase 1 (NEU1) surface expression, RCA-1 lectin binding and loss of mitochondrial inner membrane potential on donors' platelets. Sera from ITP patients with detectable antibodies caused significant platelet desialylation and apoptosis. Anti-GPIIb/IIla antibodies appeared more capable of causing NEU1 surface translocation while anti-GPIb/IX complex antibodies resulted in a higher degree of platelet apoptosis. In ITP patients with anti-GPIIb/IIla antibodies, both desialylation and apoptosis were dependent on Fc $\gamma$ RIla signaling rather than platelet activation. Finally, we confirmed in a murine model of ITP that destruction of human platelets induced by anti-GPIIb/IIla antibodies can be prevented with the NEU1 inhibitor oseltamivir. A collaborative clinical trial is warranted to investigate the utility of oseltamivir in the treatment of ITP.
\end{abstract}

\section{Introduction}

Immune thrombocytopenia (ITP) is an acquired autoimmune disease characterized by enhanced platelet destruction and impaired platelet production from megakaryocytes. ${ }^{1}$ ITP patients can present with no predisposing condition (hence, primary ITP) or with a variety of associated disorders (secondary ITP), ${ }^{2}$ such as autoimmune diseases (especially systemic lupus erythematosus), ${ }^{3}$ infections (notably Hepatitis $\mathrm{C}$ virus and HIV) ${ }^{4}$ as well as malignancies. ${ }^{5}$ Primary ITP is estimated to represent approximately $80 \%$ of all adult ITP. ${ }^{4}$ Regarding the incidence of ITP, studies from Europe have estimated that to be 2.9-3.9/100,000 annually in adults, ${ }^{6-9}$ with an overall incidence slightly higher in females than males. The prevalence is approximately 9.5-23.6/100,000.6,7,10

The pathogenesis of ITP involves antibodies recognizing membrane glycoprotein (GP) complexes. ${ }^{2,9}$ The seminal Harrington-Hollingsworth experiment of self-infusion of ITP plasma led to the discovery of a humoral factor accountable for platelet destruction in ITP.1112 Subsequently, Shulman identified that this factor could be adsorbed by platelets and was associated with immunoglobulin G (IgG). ${ }^{13}$ Currently, the widely-accepted mechanism is that antibody-coated platelets are phagocytosed by splenic and/or hepatic macrophages of the reticuloendothelial system, via their Fc $\gamma$ receptors (Fc $\gamma R$ ), resulting in accelerated platelet clearance. ${ }^{1,9,14}$ Equally important in the pathogenesis of ITP is the dysfunction of T cells. ${ }^{15}$ Both CD4 ${ }^{+}$ T-regulatory cells reduction ${ }^{16-18}$ and $\mathrm{CD}^{+} \mathrm{T}$-cell-mediated cytotoxicity ${ }^{19-21}$ have been reported in ITP. ${ }^{2,9,15}$ In addition, CD8 ${ }^{+}$T-regulatory cells' immunosuppressive role in ITP has been recognized. ${ }^{22}$ This further highlights the significant role of T cells in immune dysregulation and ITP. ${ }^{23}$ 
Antibody-mediated platelet apoptosis has also been suggested in ITP. In 2006, Leytin and colleagues reported in the mouse model that monoclonal anti-GPIIb antibody injection induced thrombocytopenia, caspase-3 activation, enhanced phosphatidylserine (PS) exposure and mitochondrial inner transmembrane potential $(\Delta \Psi \mathrm{m})$ depolarisation. ${ }^{24}$ In 2012, Winkler et al. demonstrated similar findings in pediatric patients with ITP. ${ }^{25}$ More recently, platelet apoptosis was also confirmed in adult ITP patients by Goette and colleagues. ${ }^{26}$ However, the relationship between platelet apoptosis and ITP antibody specificity was unclear, as only one patient carried sole anti-GPIb/IX antibodies in this study.

Another ITP pathway that has also been previously ${ }^{27}$ and recently ${ }^{28}$ described is $\mathrm{Fc}$-independent platelet clearance. $\mathrm{Li}$ and co-workers reported platelet desialylation through antibody-induced platelet activation by treating donor platelets with monoclonal anti-GPIb/IX antibodies and ITP sera. ${ }^{28}$ Using a murine model of ITP secondary to monoclonal anti-GPIba antibodies, the group demonstrated evidence of platelet removal via Ashwell-Morell receptors on hepatocytes, and the use of sialidase inhibitors to attenuate thrombocytopenia. ${ }^{28}$ Although the model is not directly relevant to human disease due to the absence of platelet surface FcyRIIA on mouse platelets and the polyclonal nature of primary ITP,, 29 these findings still have potential therapeutic implications: patients with antiGPIb/IX antibodies may respond to sialidase inhibitors while patients with anti-GPIIb/IIla antibodies were considered unlikely to respond to this novel treatment.

Conversely, patients who harbor anti-GPIIb/IIla antibodies possibly respond to IVIg therapy better than those with sole anti-GPIb/IX antibodies, because anti-GPIIb/IIla antibodies could drive ITP in an Fc-dependent fashion. ${ }^{23,30-32}$ Similarly, splenectomy may be ineffective in patients with only anti-GPIb/IX autoantibodies as desialylated platelets are removed by the liver. ${ }^{28}$ This differential effect and, therefore, determining antibody specificity, may influence treatment decision and ultimately patient outcomes. Nevertheless, these views have been recently challenged by Cantoni et al., who studied 93 ITP patients and found no predictability of anti-platelet antibody (APA)-specificity on the site of platelet clearance. ${ }^{33}$ Thus, ongoing investigations to determine whether antibody specificity predicts therapeutic response is vital.

The true extent to which platelet desialylation and/or platelet apoptosis are involved in ITP pathology remains unclear. Notably, both desialylated and apoptotic platelets were reported to be removed by the liver. ${ }^{28,34,35}$ Yet, platelet apoptosis was observed in a murine ITP model induced by monoclonal anti-GPIIb antibodies, ${ }^{24}$ but desialylation has been demonstrated in ITP patients with anti-GPIb ${ }^{28}$ and anti-GPIIb/IIla antibodies. ${ }^{36,37}$ Whether there is a link between platelet desialylation and platelet intrinsic apop- tosis in ITP caused by these two antibodies is still not defined. In addition, the possibility of using neuraminidase inhibitors in the treatment of ITP is also to be investigated. We recently examined the sera from 61 ITP patients for the presence of APA and their specificities. ${ }^{38}$ Here, we further scrutinize the sera's capability to induce platelet desialylation and apoptosis, and studied these two potential thrombocytopenic mechanisms' relationship with the antibody subtypes. Additionally, we established a mouse model to elucidate the therapeutic effect of neuraminidase inhibitor in preserving human platelet number in the presence of patients' antibody and provide in vivo data on the feasibility of this agent in the treatment of ITP.

\section{Methods}

\section{Patient sample collection}

The study was approved by the Human Research and Animal Care Ethics Committees of the University of New South Wales (Sydney, Australia). Sera were obtained from 61 adult ITP patients (aged between 18-90 years) and 21 healthy controls with written informed consent. All 61 patients were diagnosed with ITP according to the international working group's criteria, ${ }^{39}$ which was also consistent with the 2019 updated consensus report. ${ }^{40}$ Whole blood was centrifuged at $860 \times \mathrm{xg}$ for 10 minutes (min). The sera and plasma were stored in aliquots at $80^{\circ} \mathrm{C}$ until required for analysis. In some experiments, IgG fraction, purified using Protein $\mathrm{G}$ affinity chromatography (Sigma-Aldrich, USA), was used. The purity was over $95 \%$ as determined by gel densitometry (ImageJ, Version 2.1.0/1.53c).

\section{Anti-platelet antibody detection and specificity determination}

The indirect detection of APA and the determination of antibody specificities in this cohort of patients have recently been published. ${ }^{38}$ Briefly, venous blood was collected into $3.2 \%$ trisodium citrate. Platelet pellets were washed with wash buffer (pH 6.0) containing $140 \mathrm{mM}$ $\mathrm{NaCl}, 5 \mathrm{mM} \mathrm{KCl}, 12 \mathrm{mM}$ trisodium citrate, $10 \mathrm{mM}$ glucose, $12.5 \mathrm{mM}$ sucrose, followed by resuspension in buffer $(\mathrm{pH}$ 7.4) containing $140 \mathrm{mM} \mathrm{NaCl}, 3 \mathrm{mM} \mathrm{KCl}, 0.5 \mathrm{mM} \mathrm{MgCl}, 5$ $\mathrm{mM} \mathrm{NaHCO}, 10 \mathrm{mM}$ glucose and $10 \mathrm{mM}$ HEPES. Washed platelets $\left(1 \times 10^{6}\right)$ were incubated with patients' samples at various dilutions for $30 \mathrm{~min}$ at $37^{\circ} \mathrm{C}$, washed twice, incubated with Alexa Fluor 488 or 647-labeled anti-human IgG (Invitrogen, 1:100), washed and analyzed by flow cytometry (LSRFortessa ${ }^{\mathrm{TM}} \mathrm{X}-20$ [BD, USA]).

For antibody specificity determination, monoclonal antibody immobilization of platelet specific antigens assay (MAIPA) was performed as previously described. ${ }^{38,41}$ Donor platelets were incubated with sera, followed by washing 
and incubation with antibodies against GPIIb/IIla complex (AP2; Beckman Coulter, USA), GPIX (FMC25, Millipore, USA) or GPV (G-11, Santa Cruz Biotechnology, Inc. USA). The platelets were washed, solubilized and incubated in goat anti-mouse IgG Fc fragment-specific antibody (Jackson ImmunoResearch, USA) precoated microtiter plates (ThermoFisher, USA). The reactions were washed and further incubated with goat anti-human IgG Fc fragmentspecific-horseradish peroxidase-conjugated antibody (Sigma-Aldrich, USA). SureBlue ${ }^{\text {Tw }}$ TMB-microwell peroxidase substrate (KPL Inc. USA) was then added and stopped at $10 \mathrm{~min}$ with $0.18 \mathrm{M}$ sulphuric acid. The absorbance was read at dual wavelength (450 nm and $492 \mathrm{~nm}$ ).

\section{Platelet neuraminidase expression, desialylation and activation}

In order to examine sera-induced platelet neuraminidase expression, $1 \times 10^{6}$ washed donor platelets were incubated with patient or control sera $(1: 25)$ for $30 \mathrm{~min}$ at $37^{\circ} \mathrm{C}$ followed by washing and incubation with anti-NEU1 mouse monoclonal antibody (1:25, Santa Cruz Biotechnology, Inc. USA) for $20 \mathrm{~min}$ at room temperature and washing. Similarly, for platelet desialylation, the washed sera-donor platelet reactions were incubated with FITC-labeled Ricinus communis lectin (RCA-1, Vector Laboratories, USA, 0.5 $\mu \mathrm{g} / \mathrm{mL}$ ). In order to determine the effect of patients' IgG, control experiments were performed using purified IgG from healthy donors and ITP patients $(50 \mu \mathrm{g} / \mathrm{mL})$. Platelet activation was assessed by flow cytometry with anti-Pselectin monoclonal antibody APC (1:5, eBioscience ${ }^{\mathrm{TM}}$, Germany).

\section{Platelet apoptosis}

In order to evaluate ITP patient sera's effect on platelet mitochondrial inner membrane depolarization potential, $1 \times 10^{6}$ washed donor platelets in phosphate-buffered saline containing $1 \mathrm{mM} \mathrm{MgCl}_{2}, 5.6 \mathrm{mM}$ glucose, $10 \mathrm{mM}$ HEPES and $0.1 \%$ bovine serum albumin were incubated with patients' or controls' sera $(1: 10)$ for $30 \mathrm{~min}$ at $37^{\circ} \mathrm{C}$, followed by washing and incubation with $100 \mathrm{nM} \mathrm{DiOC}_{6}$ (Molecular Probes) for $15 \mathrm{~min}$ in the dark. In order to examine the role of Fc $\gamma \mathrm{R}$ in platelet apoptosis, platelets were pre-incubated with anti-FcyRlla antibody (clone IV.3, $2.5 \mu \mathrm{g} / \mathrm{mL}$ ) for 10 min at $37^{\circ} \mathrm{C}$ prior to treatment with patients' sera. In order to determine the effect of patients' IgG on platelet apoptosis, experiments were performed using $50 \mu \mathrm{g} / \mathrm{mL}$ of IgG, followed by washing and incubation with $50 \mathrm{nM} \mathrm{DiOC}$.

\section{NOD/SCID mouse model of immune thrombocytopenia}

Human platelets $\left(450 \times 10^{6}\right)$ were transfused via the tail vein into the non-obese diabetic/severe combined immunodeficient (NOD/SCID) mice and allowed to stabilize for 2.5 hours (h). Forty $\mu \mathrm{g} / \mathrm{g}$ of patients' or controls' IgG was then administered intravenously. ${ }^{42}$ Oseltamivir-treated mice re- ceived intraperitoneal (IP) injection of $10 \mu \mathrm{g} / \mathrm{g}$ oseltamivir immediately prior to human platelet infusion and again, immediately before IgG injection. Mouse blood was collected at time 0 (prior to IgG injection), 2, 4 and $6 \mathrm{~h}$ following IgG injection. Human platelets were identified using anti-human CD41a V450 (BD Biosciences, USA) by flow cytometry. The percentage of human platelets at time 0 was set at $100 \%$.

\section{Statistical analysis}

Flow cytometry data were processed with FlowJo software (LCC, USA). Data were analyzed with GraphPad Prism version 8 (GraphPad Software, USA). The significance level was set at less than 0.05. Kruskal-Wallis test with Dunn's multiple comparison was carried out for in vitro desialylation and apoptosis experiments. Linear mixed model was used to examine the effect of neuraminidase inhibitor on platelet survival in vivo. Mann Whitney test was applied in other analyses.

\section{Results}

\section{Patient characteristics}

Of the 61 patients (aged between 18-90 years old) included in this study, $61 \%$ were female. The majority (84\%) had primary ITP. Thirty-five patients (57\%) had detectable APA in their sera as determined by flow cytometry. MAIPA demonstrated that nine patients had sole anti-GPIIb/IIla antibodies, five patients had sole anti-GPIb/IX antibodies while seven other patients had antibodies against both complexes. The rest (14 patients, 23\%) had no detectable anti-GPIIb/IIla or anti-GPIb/IX antibodies by MAIPA (Figure 1A). ${ }^{38}$ Compared to the direct testing, ${ }^{43}$ the lower detection rate of dual antibody positive patients may reflect the lower sensitivity in antibody determination using indirect method, which is consistent with a prior MAIPA report. ${ }^{41}$ Recent work demonstrated that GPV is an important target of APA in ITP. ${ }^{44,45}$ We additionally interrogated patient samples with positive indirect APA (sera from 31 patients were available) for the presence of anti-GPV antibodies. Using a cutoff of 3 standard deviations (SD) over the mean of 20 normal controls, 21 patients were positive for antibodies against GPIIb/IIla, GPIb/IX and/or GPV (Table 1). Seven were found to have anti-GPV antibodies in their sera. However, two patients have co-existing antiGPIIb/IIla antibodies, two others have co-existing antiGPIb/IX antibodies, and one patient had all three antibodies (Table 1; Figure 1B).

\section{Anti-platelet antibodies predict platelet desialylation}

In order to determine whether ITP patients' sera can induce desialylation, we treated donor platelets with ITP or control sera and measured NEU1 expression by flow cyto- 

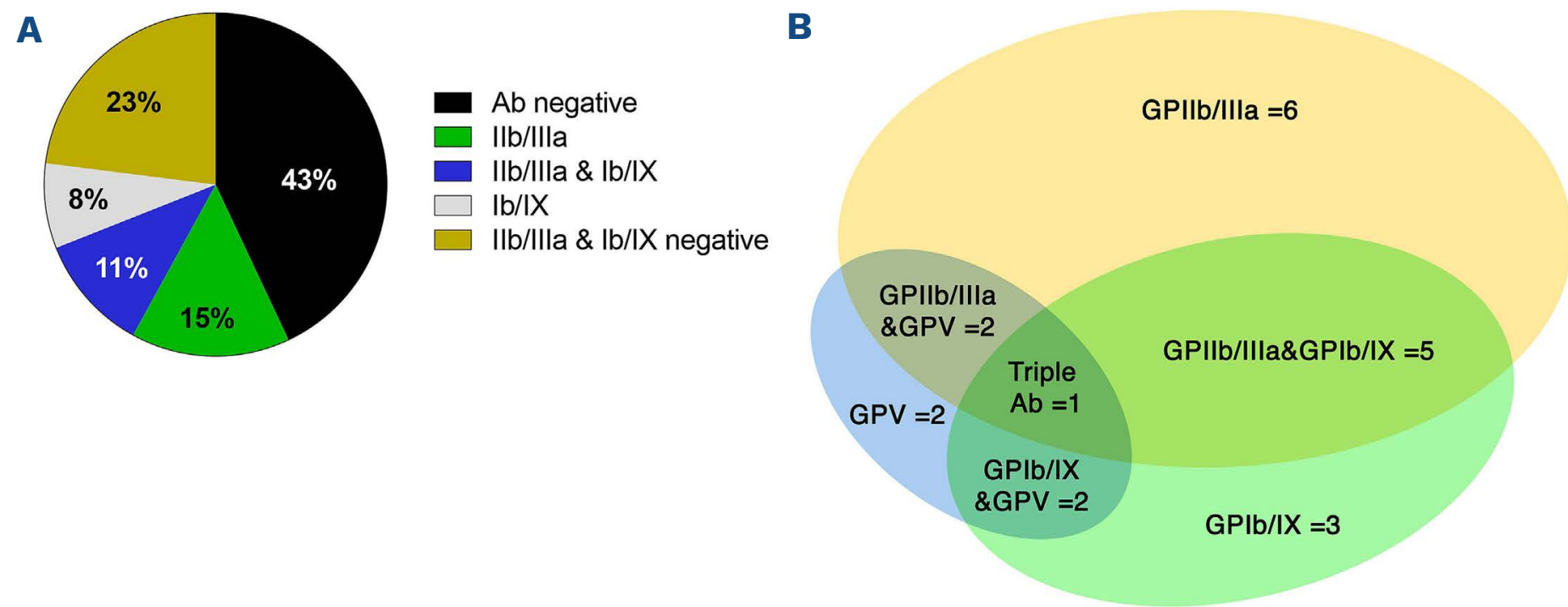

Figure 1. Antibody pattern by indirect flow cytometry and monoclonal antibody immobilization of platelet-specific antigen assay. (A) Focusing on GPIIb/IIla and GPIb/IX in 61 immune thrombocytopenia (ITP) patients, $43 \%$ had no detectable antibodies by flow cytometry (Ab negative); of the 35 patients with positive antibody by flow cytometry, $15 \%$ had antibodies against GPIIb/IIla (IIb/IIla); $8 \%$ against GPIb/IX (Ib/IX); $11 \%$ had antibodies against both complexes (Ilb/IIla \& Ib/IX). (B) Examination of anti-GPV antibody by monoclonal antibody immobilization of platelet-specific antigen assay (MAIPA) in 31 patients with available sera, in relation to anti GPIIb/IIla and GPIb/IX antibodies. GP: glycoprotein.

metry. NEU1 expression was significantly increased in ITP sera-treated platelets compared to controls (Figure 2A). Further scrutiny of the patient subgroups, determined by the antibody status, demonstrated that NEU1 translocation was significantly different from controls only in platelets treated with sera from patients with detectable APA (Figure 2B). Indeed, when we examined the level of platelet desialylation, as assessed by RCA-1 binding, we found that only antibody-positive sera could induce detectable desialylation (Figure $2 \mathrm{C}$ ). Of note, a significant difference in RCA-1 binding was not detected when comparing the whole ITP group (antibody-positive and negative sera) to normal controls (Figure 2D). This is likely due to the weak binding of lectins (such as RCA-1) to their target sugars. ${ }^{46}$

We further examined whether the IgG fraction was responsible for platelet desialylation. We used purified IgG

Table 1. Summary of anti-platelet antibodies found in sera as determined by monoclonal antibody immobilization of platelet-specific antigens assay.

\begin{tabular}{l|c|c}
\hline & Patient $\mathbf{N}$ & Patient \% \\
\hline GPIlb/IIla & 6 & 28.6 \\
\hline GPIb/IX & 3 & 14.3 \\
\hline GPV & 2 & 9.5 \\
\hline GPIIb/IIla+GPIb/IX & 5 & 23.8 \\
\hline GPIIb/IIla+GPV & 2 & 9.5 \\
\hline GPIb/IX+GPV & 2 & 9.5 \\
\hline GPIIb/IIla+GPIb/IX+GPV & 1 & 4.8 \\
\hline Total & 21 & 100.00 \\
\hline
\end{tabular}

GP: glycoprotein. from two ITP patients containing anti-GPIIb/IIla antibodies to treat donor's platelets. Figure 2E shows that the IgG fraction causes significant platelet desialylation. This result confirmed the findings by Marini and colleagues, that ITP patients' IgG leads to cleavage of platelets' sialic acid and hence, platelet desialylation. ${ }^{36}$ Together, these data show that ITP autoantibodies induce NEU1 translocation and platelet desialylation.

Given the previous observation of platelet activation by monoclonal antibodies against GPIba causing platelet desialylation, ${ }^{28}$ we examined the ability for ITP patients' sera to induce P-selectin externalization. Compared to the control group, there was no enhanced anti-CD62P binding to treated platelets (Figure 2F). Unlike NEU1 expression and desialylation, no difference in platelet activation was noted between sera from patients with or without detectable APA (Figure 2G). Interestingly, the three sera with the highest $\mathrm{P}$-selectin expression were all from secondary ITP patients (systemic lupus erythematosus [SLE], anti-phospholipid syndrome [APS] and B-cell lymphoma), raising the likelihood of distinct disease biology in secondary ITP. Finally, no difference was seen when patients with GPIIb/IIla APA were compared with those with anti-GPIb/IX antibodies (Figure $2 \mathrm{H}$ ).

\section{Anti-platelet antibodies predict platelet apoptosis}

In order to determine the role of ITP auto-antibodies in platelet apoptosis, washed platelets were treated with either ITP or control sera. Like NEU1 expression, upon treatment with patients' sera, platelets showed significantly reduced $\mathrm{DiOC}_{6}$ fluorescence compared to the control (Figure 3A). This denotes the loss of mitochondrial inner membrane potential, $\Delta \Psi \mathrm{m}$, indicating the presence of platelet apoptosis. Consistent with the observations for 
desialylation, when compared to the controls, antibody positive patients' sera disrupted mitochondrial $\Delta \Psi \mathrm{m}$ more effectively than the antibody negative group (Figure 3B). Importantly, these changes are induced by the IgG fraction of ITP sera (Figure 3C). Therefore, the presence of APA in ITP sera induces platelet apoptosis as determined by changes in mitochondrial $\Delta \Psi \mathrm{m}$.

\section{Anti-GPIIb/IIla antiplatelet antibodies induce platelet apoptosis via Fcy receptor}

Prior literature demonstrated that the platelet desialylating capacity of anti-GPIb $\alpha$ antibody was FcyR-independent. ${ }^{28}$ However, in the case of anti-GPIIb/IIla antibodies induced ITP, we and others have shown that FcyR is the driver of antibody-mediated platelet desialylation. ${ }^{36,37} \mathrm{Also}$
A

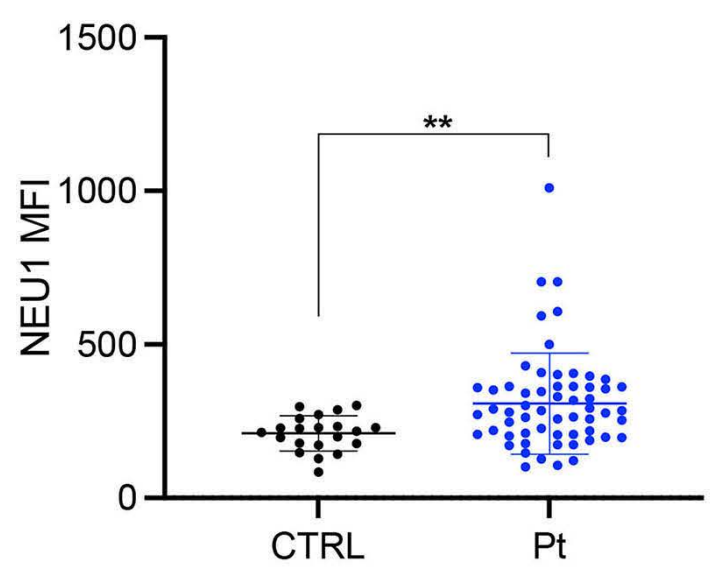

C

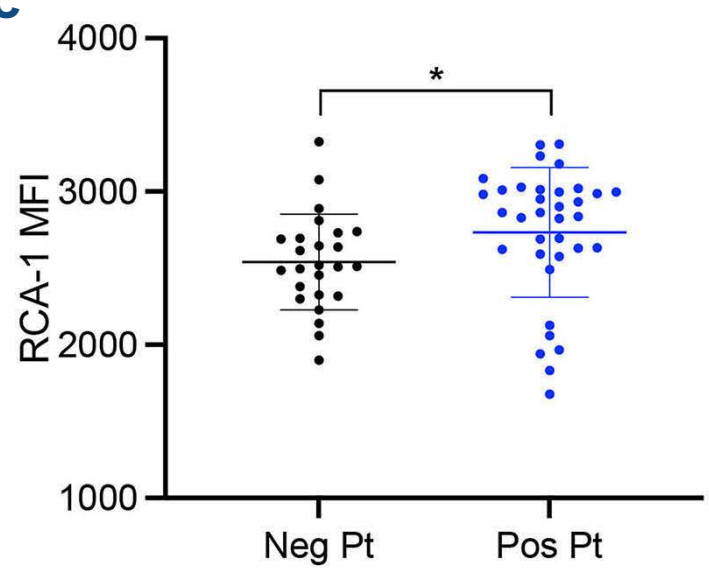

E

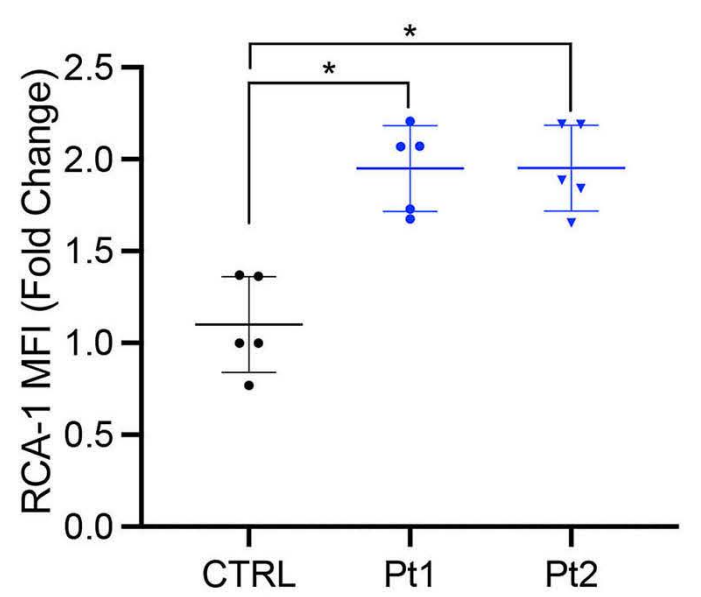

G

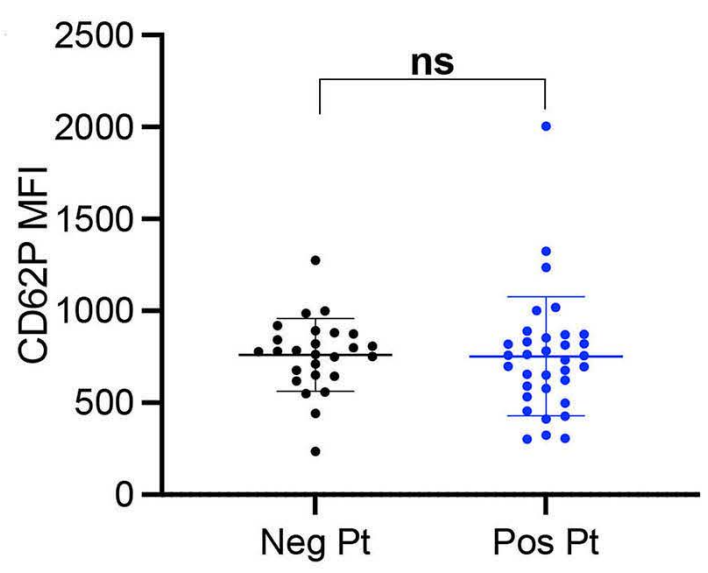

B

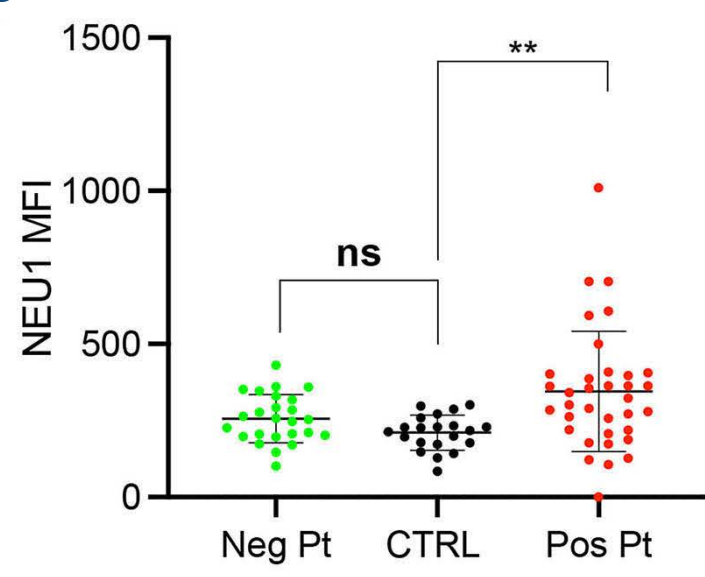

D

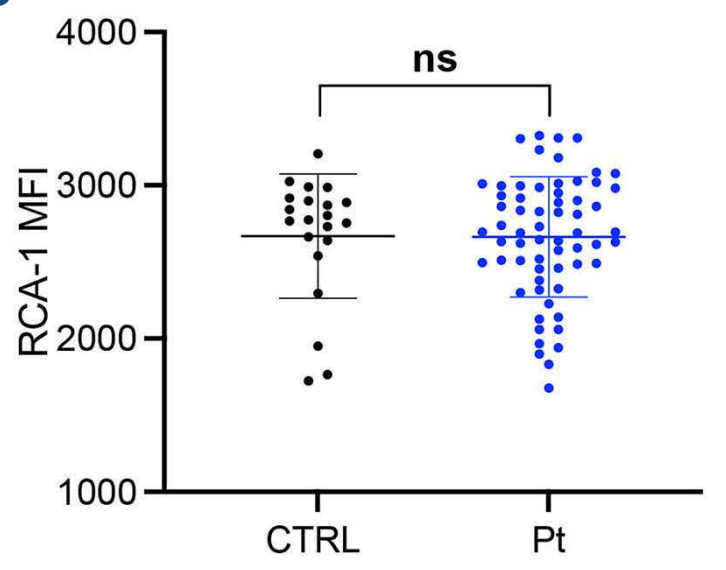

$\mathbf{F}$

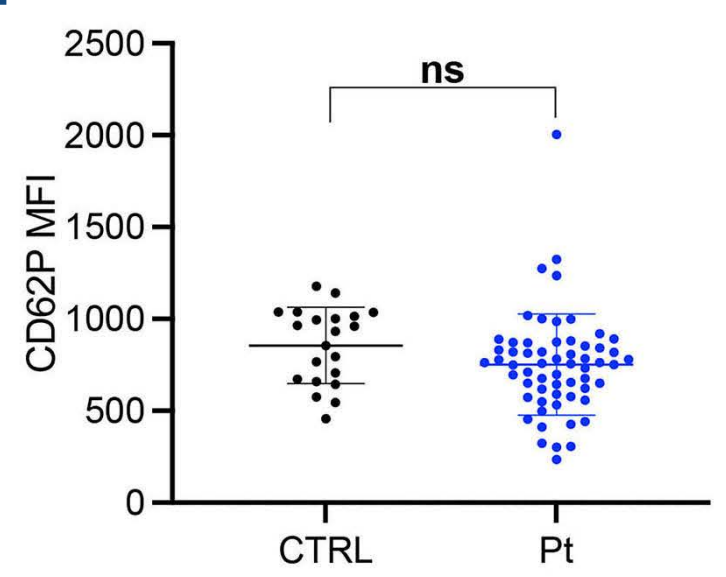

$\mathbf{H}$

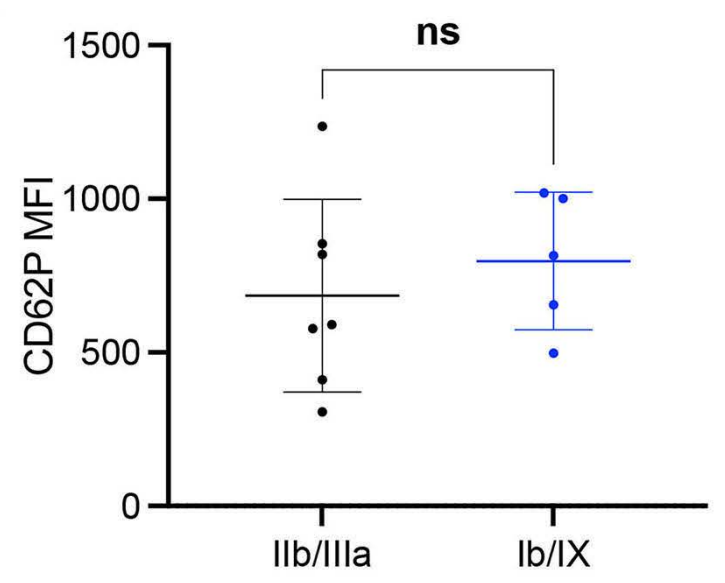

Figure 2. Effect of immune thrombocytopenia patient sera on platelet desialylation and activation. ( $A$ and $B$ ) NEU1 surface translocation and ( $C$ and $D)$, RCA1 lectin binding comparing patient subgroups and controls. (E) Effect of purified immune thrombocytopenia (ITP) immunoglobulin $\mathrm{G}$ (IgG) $(50 \mu \mathrm{g} / \mathrm{mL})$ on RCA-1 lectin binding. ( $F$ and $G$ ) P-selectin expression on control and patient sera treated platelets. (H) P-selectin expression on platelets treated with GPIIb/IIla or GPIb/IX antibodies. CTRL: control; Pt: patient; Neg: antibodynegative; Pos: antibody-positive; MFI: mean fluorescence intensity. Data shown as mean \pm standard deviation. Levels of significance are expressed as $P$-values. ns: non-significant, ${ }^{*} P<0.05, * *, P<0.01$. Mann Whitney and Kruskal-Wallis test with Dunn's multiple comparison. 
clinically relevant is that, anti-GPIIb/IIla auto-antibodies account for the majority of antibody positive cases in our patient population (Figure 1B), which is consistent with a recent report. ${ }^{43}$ Therefore, further examination into the pathogenesis of anti-GPIIb/IIla antibody driven ITP is of clinical significance.

In order to establish the relationship amongst antiGPIIb/IIla antibodies, platelet Fc $\gamma R$ and platelet apoptosis in ITP, we evaluated the impact of FcyRIIA inhibition with the monoclonal antibody IV.3 on platelet apoptosis. Platelets were treated with patient sera with or without the presence of IV.3, and the effect on platelet $\triangle \Psi \mathrm{m}$ was examined. In the presence of Fc $\gamma$ RIIA inhibitor, APA' ability to induce loss of $\Delta \Psi \mathrm{m}$ was impaired (Figure $3 \mathrm{D}$ ). The rise in $\Delta \Psi \mathrm{m}$ in platelets pretreated with IV.3 was quantified and is shown in Figure 3E. This observation indicates that the anti-GPIIb/IIla auto-antibodies signal via FcyRIIA to initiate platelet apoptosis pathway.

\section{Anti-platelet antibodies have differential effects on the thrombocytopenic pathway}

We further examined the differential effects of the most common APA's on platelet desialylation and apoptosis. Although only nine sera contained anti-GPIIb/IIla without the presence of anti-GPIb/IX antibodies, six of these antibodies induced NEU1 translocation (defined as mean fluorescence intensity [MFI] greater than 2SD of the controls). In contrast, only one of the five sera with antiGPIb/IX antibodies, without anti-GPIIb/IIla, was able to do so (Figure 4A, table 2). To our surprise, four of these five anti-GPIb/IX sera led to platelet apoptosis as reflected by significant loss of $\Delta \Psi \mathrm{m}$ (defined as MFI lower than 2SD of the controls) while only three of the nine anti-GPIIb/IIla sera induced this change (Figure 4B; Table 2). Together, these novel findings indicate that APA specificity is an important determinant of platelet fate in ITP and the missing link between the previously unobserved relationship between platelet desialylation and apoptosis. ${ }^{36}$

Two patient sera were found to have sole anti-GPV antibodies. Repeated experiments using these two sera did not show evidence of desialylation on donor platelets (Figure 5A). However, treatment of donor platelets using one of the two patients' sera produced significant reduction of DiOC6 fluorescence (Figure 5B). The second
A
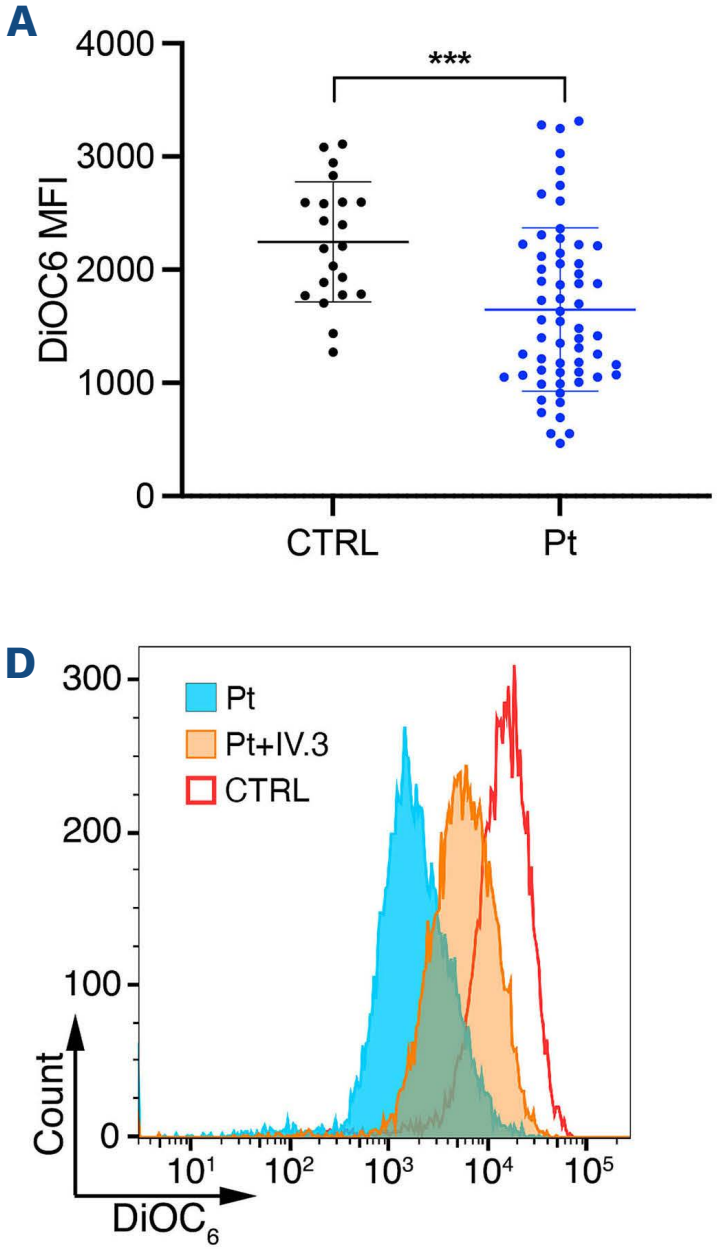
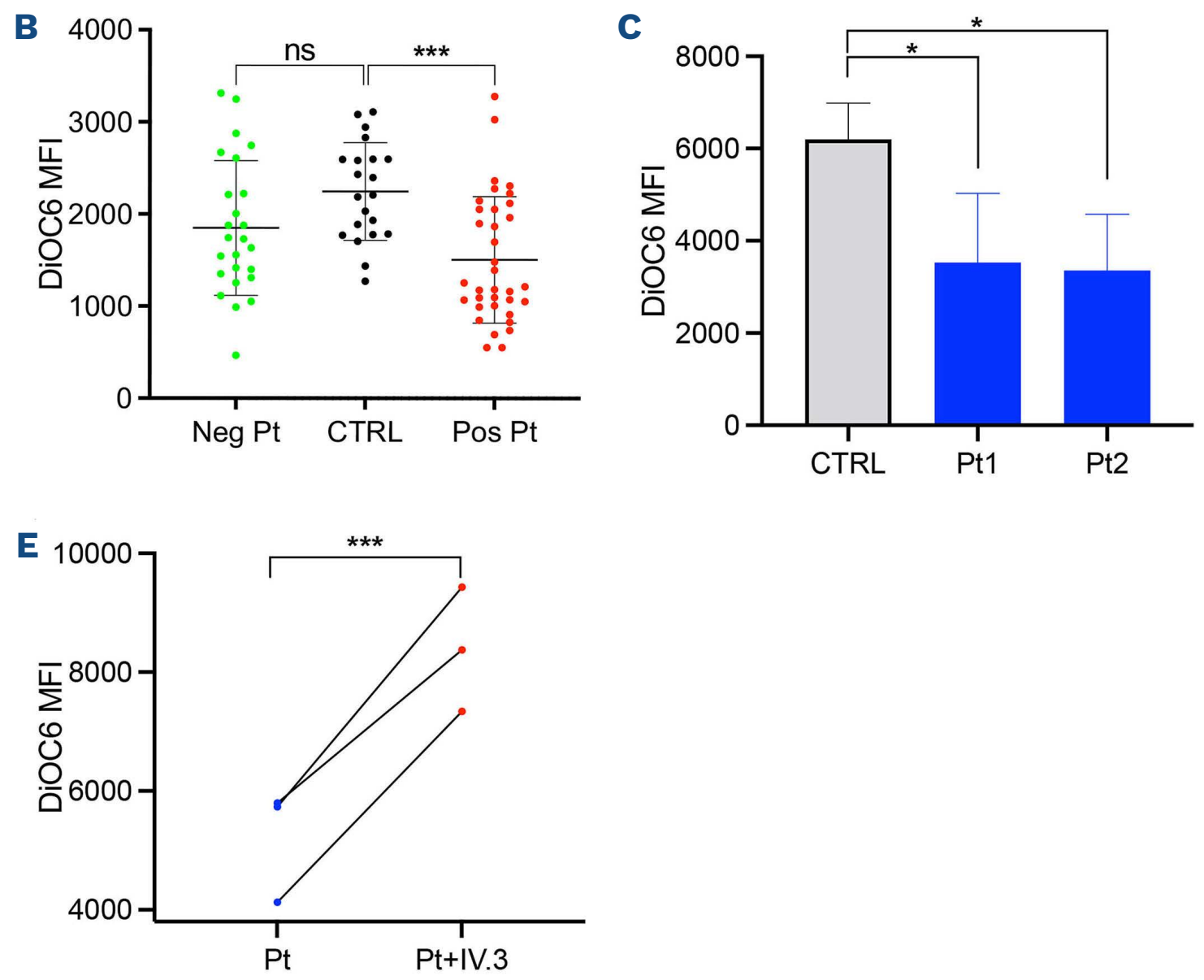

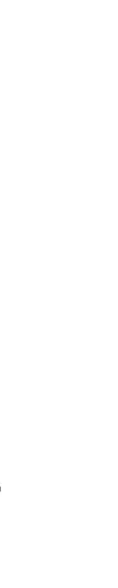

Figure 3. Effect of immune thrombocytopenia sera on platelet apoptosis. Loss of mitochondrial inner transmembrane potential $(\triangle \Psi \mathrm{m})$ as measured by $\mathrm{DiOC}_{6}$ in platelets treated by $(\mathrm{A})$ immune thrombocytopenia (ITP) patients' (Pt) and controls' sera (CTRL), as well as (B) antibody-positive (Pos) and antibody-negative (Neg) patients' sera. (C) Effect of purified ITP immunoglobulin G (IgG) $(50 \mu \mathrm{g} / \mathrm{mL})$ on washed platelets. (D) Histogram representing the effect of anti-FcyRlla antibody IV.3 on $\Delta \Psi \mathrm{m}$ despite the presence of patient sera. (E) Effect of anti-FcyRlla antibody IV.3 on $\Delta \Psi \mathrm{m}$ of 3 patients; data point represents the mean of 3 experiments. MFI: mean fluorescence intensity. Data shown as mean \pm standard deviation. Levels of significance are expressed as $P$-values. ns: non-significant, ${ }^{*} P<0.05, * \star \star P<0.001$. Mann Whitney and Kruskal-Wallis test with Dunn's multiple comparison. Repeated measures ANOVA used in 3E. 
Table 2. Relative effects of anti-GPIIb/IIla and anti-GPIb/IX antibodies on platelet desialylation and apoptosis.

\begin{tabular}{|l|c|c|}
\hline \multicolumn{1}{|c|}{ Effect } & $\begin{array}{c}\text { Anti-GPIIb/IIIa } \\
\text { sera }\end{array}$ & $\begin{array}{c}\text { Anti-GPIb/IX } \\
\text { sera }\end{array}$ \\
\hline Positive NEU1 translocation & $67 \%$ & $20 \%$ \\
\hline Significant loss of $\Delta \Psi_{\mathrm{m}}$ & $33 \%$ & $80 \%$ \\
\hline
\end{tabular}

GP: glycoprotein; $\Delta \Psi \mathrm{m}$ : mitochondrial inner transmembrane potential.

sample also led to decreased $\Delta \Psi \mathrm{m}$ compared to controls but was not statistically significant $(P=0.15$; Kruskal Wallis with Dunn's multiple comparison), indicating that antiGPV APA possibly lead to platelet apoptosis. A larger sample size with sole anti-GPV antibody is needed to assess its functional effect on platelets.

\section{Oseltamivir protects platelets from GPIIb/IIla antibody mediated destruction in vivo}

Neuraminidase inhibitor oseltamivir has been previously reported to protect platelets from anti-GPIba monoclonal antibody driven platelet destruction in murine studies. ${ }^{28}$ More recently, we demonstrated oseltamivir's effect on platelet number preservation in the presence of polyclonal human anti-GPII/IIla antibody from a patient with acquired Glanzmann Thrombasthenia. ${ }^{37}$ Following our findings that anti-GPIIb/IIla antibodies induce desialylation (Figure 4A), we extended our in vivo experiments to examine other ITP patients with sole anti-GPIIb/IIla antibodies. In order to test whether destruction of human platelets could be prevented in vivo, we treated recipient mice with oseltamivir. As shown in Figure 6, oseltamivir protected human platelets from anti-GPIIb/IIla antibodymediated destruction. Therefore, the protective effect of desialylation inhibitors could be generalized to patients with anti-GPIIb/IIla antibodies. Oseltamivir reduces platelet destruction in ITP and is potentially an efficacious treatment for a larger proportion of ITP patients as antiGPIIb/IIla antibody is a more common antibody than antiGPIba antibody.

\section{Discussion}

ITP is a heterogenous disease with multiple proposed mechanisms. Potential therapeutic advances require more detailed understanding of the means that lead to platelet destruction. As such, we sought to examine platelet desialylation and apoptosis as contributors to thrombocytopenia in ITP. We studied 61 ITP patient sera and examined the presence of APA as a predictor for these two processes. Antibody specificity was interrogated, specifically, anti-GPIb/IX, anti-GPIIb/IIla and GPV antibodies. GPIa was not examined as isolated anti-GPla/lla antibody positivity has not been reported in recent literature. ${ }^{43,47}$ We demonstrated that the presence of APA in ITP patients' sera is associated with platelet desialylation in our patient population. Although desialylation was initially thought to be induced by anti-GPIb/IX antibodies in ITP, ${ }^{28}$ here we found that enhanced neuraminidase expression was observed in the majority of our patient cohort with detectable APA. This supports recent studies which reported that the loss of sialic acid is a more frequent finding in ITP than previously thought. ${ }^{36,48}$ Furthermore, in a murine model of ITP utilising patients' anti-GPIIb/IIla antibodies and human platelets, we found solid and reproducible ${ }^{36}$ evidence to support the use of neuraminidase inhibitors as potential new therapeutics for ITP.

The status of whether the patients have detectable ITP antibodies also influences the degree of platelet apoptosis. Sera with ITP antibodies induced significantly greater loss of $\Delta \Psi \mathrm{m}$ compared to the controls, which was not observed in the antibody-negative group. As we and others have found that desialylation depends on FcR activity in
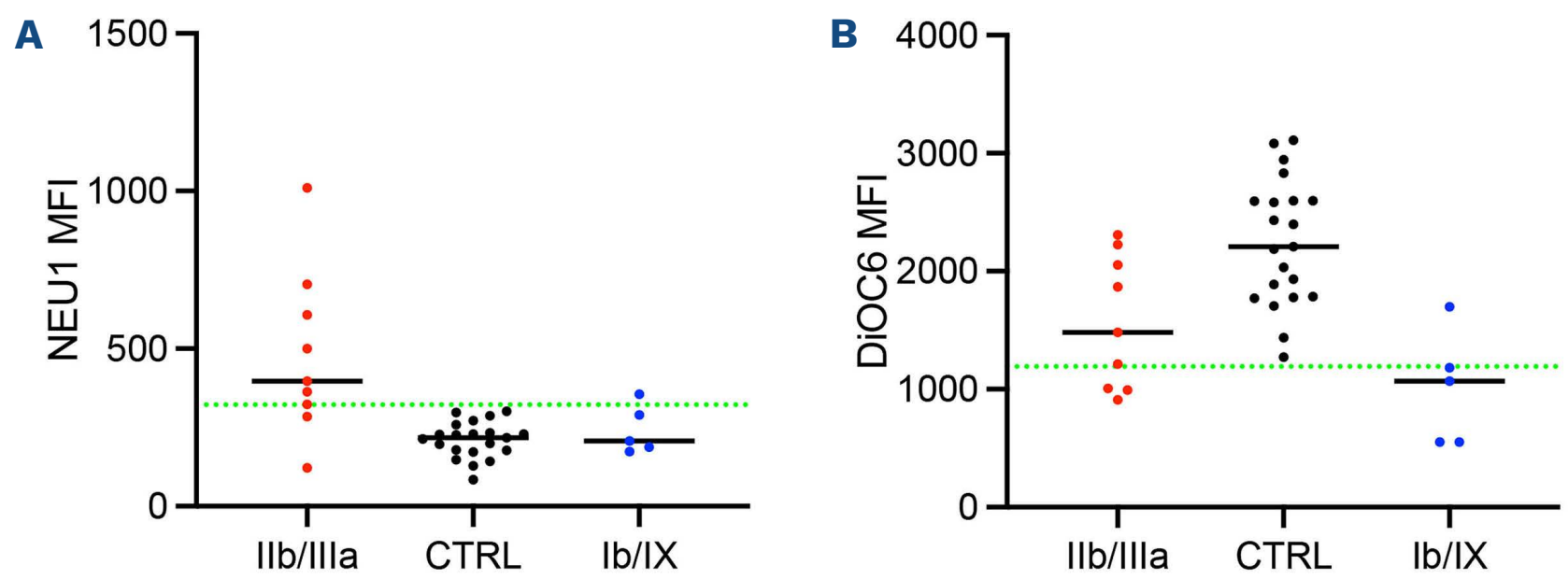

Figure 4. Differential effect of anti-GPIIb/IIla and anti-GPIb/IX antibodies on NEU1 surface translocation and mitochondrial inner transmembrane potential. (A) Effect on NEU1 surface translocation and (B) on mitochondrial inner transmembrane potential $(\Delta \psi \mathrm{m})$. CTRL: control. Black horizontal lines represent the means for each group. Green horizontal lines indicate the cutoff for positive samples (2SD over [for NEU1] and under [for DIOC 6 ] the average of controls). Two patients in the anti-GPIIb/IIIa antibody subgroup and 2 patients in the anti-GPIb/IX subgroup had concomitant anti-GPV antibodies. MFI: mean fluorescence intensity. 
anti-GPIIb/IIIa antibody-driven ITP, ${ }^{36,37}$ we further examined the relationship between platelet Fc $\gamma \mathrm{R}$ and the downstream signaling of these ITP antibodies in platelet apoptosis. FcyRlla inhibitor IV.3 effectively suppressed antibody-induced platelet loss of $\Delta \Psi \mathrm{m}$, indicating that anti-GPIIb/IIla antibodies may signal through Fc $\gamma R$ to initiate platelet apoptosis.

In addition to the ability to predict desialylation and apoptosis, antibody specificity appears to have an impact on the predominant thrombocytopenic mechanism in ITP. Unlike a prior report, ${ }^{28}$ we found that anti-GPIIb/IIla antibodies resulted in higher degree of NEU1 translocation. On the other hand, anti-GPIb/IX antibodies appeared to cause more platelet apoptosis. A recent systematic study examined antibody specificity and platelet/megakaryocyte desialylation..$^{36}$ The report described no association between antibody-induced desialylation and platelet apoptosis in
ITP. ${ }^{36}$ However, this study did not report the relationship between antibody specificity and the induction of either desialylation or apoptosis. In our study, the finding of differential effects with respect to the antibody specificity provides a potential new dimension to the understanding of ITP pathogenesis.

The small number of patients containing sole anti-GPV antibodies precludes definite conclusions on its effect on the subsequent platelet events, but it is notable that sera from both patients did not induce desialylation. Interestingly, this result is consistent with the finding by Amini and colleagues, who recently reported the lack of hepatic uptake of Indium-111 labeled platelet in patients with antiGPV antibodies. ${ }^{49}$ Of note, serum from one anti-GPV positive patient induced significant loss of platelet $\Delta \Psi \mathrm{m}$, indicating anti-GPV may drive ITP via platelet apoptosis. While APA testing is available in specialized platelet lab-
A

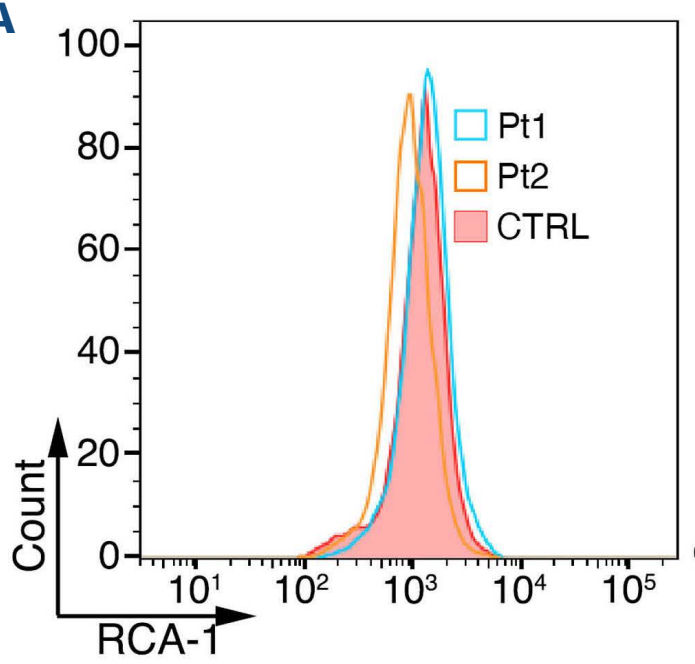

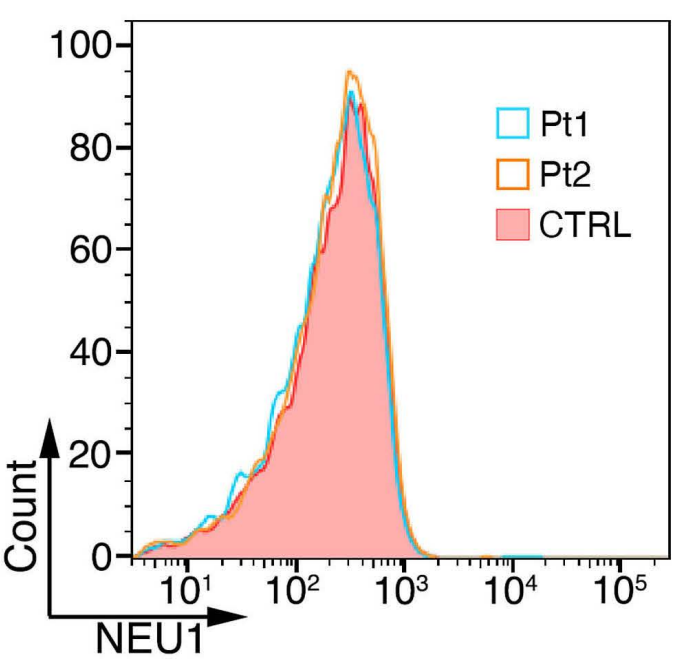

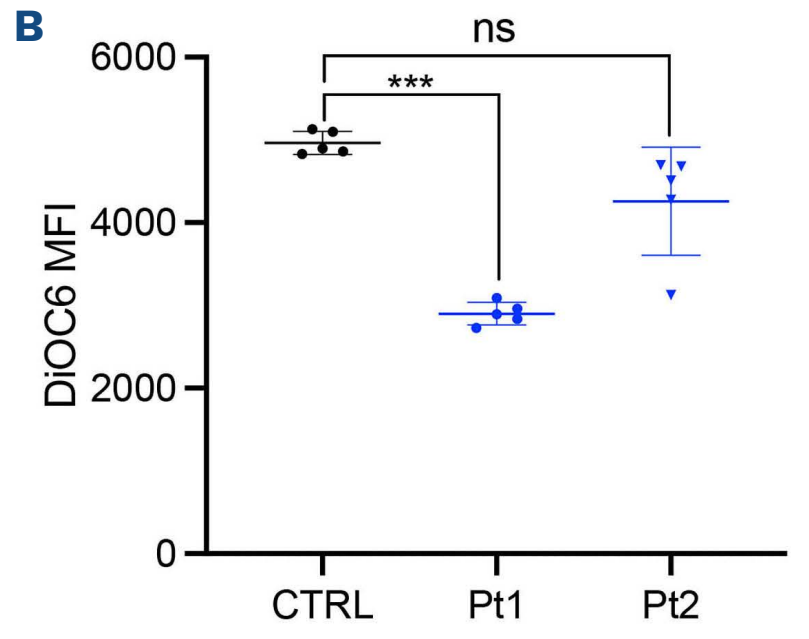

Figure 5. Effect of anti-GPV antibodies on platelet desialylation and apoptosis. (A) Effect on desialytion and (B) on apoptosis. CTRL: control; Pt: patient. Data shown as mean \pm standard deviation. ns: non-significant, $* * * P<0.001$. Kruskal-Wallis test with Dunn's multiple comparison. MFI: mean fluorescence intensity.

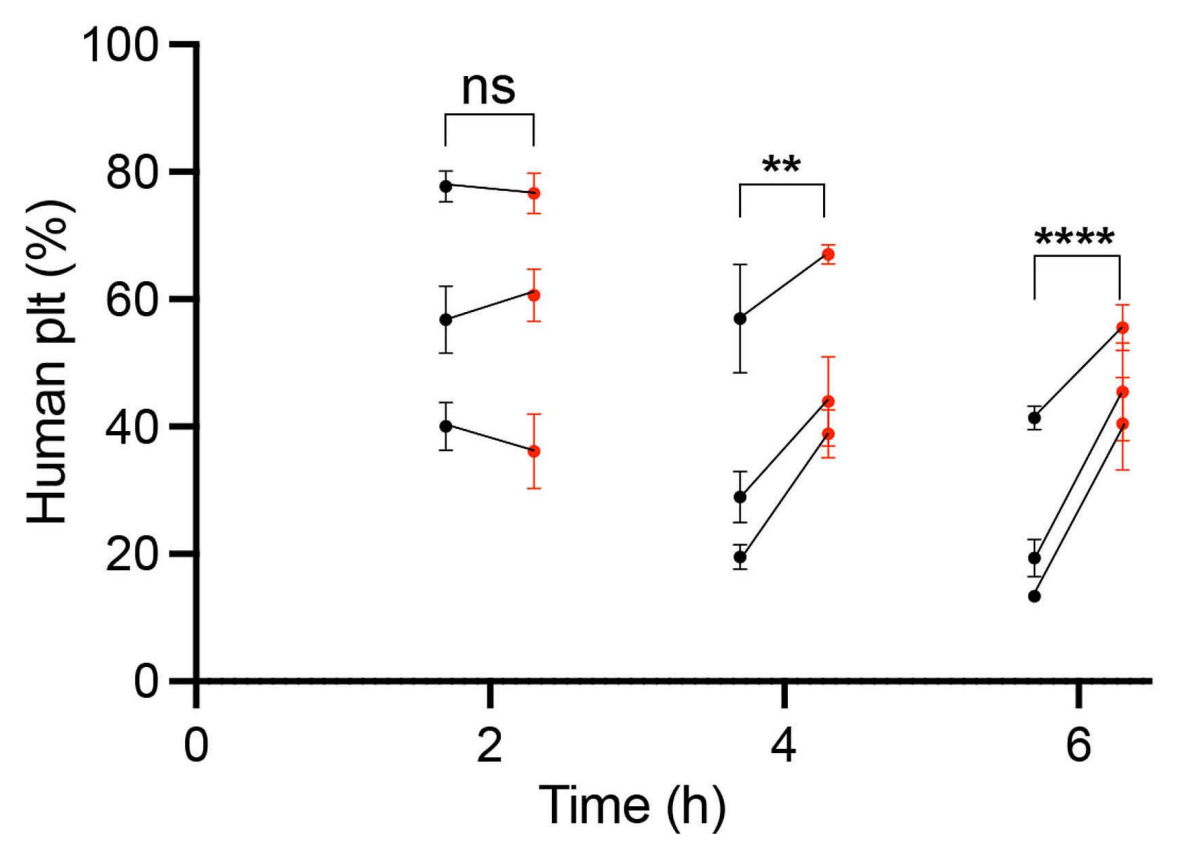

-Pt lgG

-Pt IgG+Oseltamivir

Figure 6. Murine model of immune thrombocytopenia with anti-GPIIb/IIla antibodies. Effect of 3 immune thrombocytopenia (ITP) patients' (Pt) immunoglobulin G (IgG) (black dots) and oseltamivir treatment (red dots) in the presence of patient IgG, on human platelet (plt) survival in NOD/SCID mice ( $n=5$ for each patient group) measured as human platelet percentage at 2, 4, and 6 hours after IgG injection. Data shown as mean \pm standard error of the mean. Levels of significance are expressed as $P$-values. ns: nonsignificant, $* * P<0.01, * * * \star P<0.0001$. Linear mixed model. NOD/SCID: non-obese diabetic/severe combined immunodeficient. 
oratories, routine testing has not been recommended, and ITP remains a disease without any confirmatory investigation or a "gold standard" test. Given the additional important information provided by a positive result, which is the ability of patients' antibodies to induce platelet desialylation and apoptosis, we suggest ITP antibody testing to be incorporated into ITP management algorithm. It may provide new insight into ITP pathology and could guide treatment individualization.

The main weakness of our study is that it was performed on stored patient samples. Prospective evaluation of pathological ITP sera would allow us to correlate the sera's ability to induce desialylation and apoptosis with patients' treatment and disease response. Another significant limitation in using stored samples is the lack of direct testing on patient platelets. Direct glycoprotein-specific APA assays will improve testing sensitivity ${ }^{43,50}$ and is the recommended test by the International Society of Thrombosis and Hemostasis (ISTH). ${ }^{51}$ Nevertheless, indirect examination allowed us to determine the impact of APA present in the patient serum on donor platelets and compared such effect of different patient samples as well as with controls.

Another limitation is the small number of patients with single APA specificity. Larger sample size is desirable to capture the difference between each antibody type and the associated downstream effect on platelet survival more accurately, which may ultimately lead to ITP treatment individualization. An additional challenge is the difficulties in performing platelet antibody testing outside specialized laboratories. In agreement with the ISTH recommendation, we recommend referral of platelet immunology tests to a centralized laboratory, where staff are adequately trained in specialized methods to minimize laboratory variability. ${ }^{51}$

In conclusion, we report the predictive capability of APA in relation to the potential underlying ITP mechanisms, specifically platelet desialylation and apoptosis. We showed the differential effects of antibody subtypes on these two ITP pathogenesis pathways and the role of Fc $\gamma R$ on anti-GPIIb/IIla antibodies induced platelet apoptosis.
We also demonstrated the therapeutic effect of neuraminidase inhibitor in platelet preservation despite the presence of anti-GPIIb/IIla antibodies. Hence, such treatment can potentially be applied to most ITP patients since it is likely that both anti-GPIIb/IIla antibodies (this study) and anti-GPIb/IX antibodies ${ }^{28}$ lead to platelet desialylation. Further collaboration is required to investigate the treatment potential using neuraminidase and/or apoptosis inhibitors in prospective randomized ITP clinical trials.

\section{Disclosures}

No conflicts of interest to disclose.

\section{Contributions}

SSZ designed and performed experiments, collected, and analyzed the data, and wrote the manuscript; ZA, HHLL, RW, FY performed the experiments; JSP and BHC contributed equally, provided project supervision, and reviewed the manuscript. All authors read and approved the manuscript.

\section{Acknowledgements}

The authors thank Dr. Zhixin Liu (Stats Central, UNSW) for her statistical expertise.

\section{Funding}

This work was supported by the National Health and Medical Research Council project grant to BHC (GNT 1012409) as well as St. George and Sutherland Medical Research Foundation Grant to JSP. SSZ received NSW Ministry of Health PhD Scholarship. In Vivo data presented in this work was acquired at the Mark Wainright Analytical Centre (MWAC) of UNSW Sydney, which is in part funded by the Research Infrastructure Program of UNSW.

\section{Data-sharing statement}

Data that support the findings of this study are available from the corresponding author upon reasonable request. All data generated or analysed are included in this published article.

\section{References}

1. Johnsen J. Pathogenesis in immune thrombocytopenia: new insights. Hematology Am Soc Hematol Educ Program. 2012;2012:306-312.

2. Zufferey A, Kapur R, Semple JW. Pathogenesis and therapeutic mechanisms in immune thrombocytopenia (ITP). J Clin Med. 2017;6(2):16.

3. Arkfeld DG, Weitz IC. Immune thrombocytopenia in patients with connective tissue disorders and the antiphospholipid antibody syndrome. Hematol Oncol Clin North Am. 2009;23(6):1239-1249.
4. Cines DB BJ, Liebman HA, Luning Prak ET. The ITP syndrome: pathogenic and clinical diversity. Blood. 2009;113(26):6511-6521.

5. Krauth MT, Puthenparambil J, Lechner K. Paraneoplastic autoimmune thrombocytopenia in solid tumors. Crit Rev Oncol Hematol. 2012;81(1):75-81.

6. Abrahamson PE, Hall SA, Feudjo-Tepie M, Mitrani-Gold FS, Logie $J$. The incidence of idiopathic thrombocytopenic purpura among adults: a population-based study and literature review. Eur $J$ Haematol. 2009;83(2):83-89.

7. Schoonen WM, Kucera G, Coalson J, et al. Epidemiology of im- 
mune thrombocytopenic purpura in the General Practice Research Database. Br J Haematol. 2009;145(2):235-244.

8. Moulis G, Palmaro A, Montastruc JL, Godeau B, Lapeyre-Mestre M, Sailler L. Epidemiology of incident immune thrombocytopenia: a nationwide population-based study in France. Blood. 2014;124(22):3308-3315.

9. Audia S, Mahévas M, Nivet M, Ouandji S, Ciudad M, Bonnotte B. Immune thrombocytopenia: recent advances in pathogenesis and treatments. Hemasphere. 2021;5(6):e574-e574.

10. Segal JB, Powe NR. Prevalence of immune thrombocytopenia: analyses of administrative data. J Thromb Haemost. 2006;4(11):2377-2383.

11. Harrington WJ, Minnich V, Hollingsworth JW, Moore CV. Demonstration of a thrombocytopenic factor in the blood of patients with thrombocytopenic purpura. J Lab Clin Med. 1951;38(1):1-10.

12. Schwartz RS. Immune thrombocytopenic purpura--from agony to agonist. N Engl J Med. 2007;357(22):2299-2301.

13. Shulman NR, Marder VJ, Weinrach RS. Similarities between known antiplatelet antibodies and the factor responsible for thrombocytopenia in idiopathic purpura. Physiologic, serologic and isotopic studies. Ann N Y Acad Sci. 1965;124(2):499-542.

14. Cines DB, Cuker A, Semple JW. Pathogenesis of immune thrombocytopenia. Presse Med. 2014;43(4P2):e49-e59.

15. Semple JW, Rebetz J, Maouia A, Kapur R. An update on the pathophysiology of immune thrombocytopenia. Curr Opin Hematol. 2020;27(6):423-429.

16. Stasi R, Cooper N, Del Poeta G, et al. Analysis of regulatory Tcell changes in patients with idiopathic thrombocytopenic purpura receiving $B$ cell-depleting therapy with rituximab. Blood. 2008;112(4):1147-1150.

17. Liu B, Zhao H, Poon MC, et al. Abnormality of CD4(+)CD25(+) regulatory $T$ cells in idiopathic thrombocytopenic purpura. Eur $\mathrm{J}$ Haematol. 2007;78(2):139-143.

18. Ling Y, Cao X, Yu Z, Ruan C. Circulating dendritic cells subsets and $C D 4+F o x p 3+$ regulatory $T$ cells in adult patients with chronic ITP before and after treatment with high-dose dexamethasome. Eur J Haematol. 2007;79(4):310-316.

19. Olsson B, Andersson PO, Jernas M, et al. T-cell-mediated cytotoxicity toward platelets in chronic idiopathic thrombocytopenic purpura. Nat Med. 2003;9(9):1123-1124.

20. Zhang F, Chu X, Wang L, et al. Cell-mediated lysis of autologous platelets in chronic idiopathic thrombocytopenic purpura. Eur $\mathrm{J}$ Haematol. 2006;76(5):427-431.

21. Zhao C, Li X, Zhang F, Wang L, Peng J, Hou M. Increased cytotoxic T-lymphocyte-mediated cytotoxicity predominant in patients with idiopathic thrombocytopenic purpura without platelet autoantibodies. Haematologica. 2008;93(9):1428-1430.

22. Ma L, Simpson E, Li J, et al. CD8 ${ }^{+} \mathrm{T}$ cells are predominantly protective and required for effective steroid therapy in murine models of immune thrombocytopenia. Blood.

2015;126(2):247-256.

23. Swinkels M, Rijkers M, Voorberg J, Vidarsson G, Leebeek FWG, Jansen AJG. Emerging concepts in immune thrombocytopenia. Front Immunol. 2018;9:880.

24. Leytin V, Mykhaylov S, Starkey AF, et al. Intravenous immunoglobulin inhibits anti-glycoprotein IIb-induced platelet apoptosis in a murine model of immune thrombocytopenia. $\mathrm{Br} \mathrm{J}$ Haematol. 2006;133(1):78-82.

25. Winkler J, Kroiss S, Rand ML, et al. Platelet apoptosis in paediatric immune thrombocytopenia is ameliorated by intravenous immunoglobulin. Br J Haematol. 2012;156(4):508-515.

26. Goette NP, Glembotsky AC, Lev PR, et al. Platelet apoptosis in adult immune thrombocytopenia: insights into the mechanism of damage triggered by auto-antibodies. PLoS One. 2016;11(8):e0160563.

27. Nieswandt B, Bergmeier W, Rackebrandt K, Gessner JE, Zirngibl $H$. Identification of critical antigen-specific mechanisms in the development of immune thrombocytopenic purpura in mice. Blood. 2000;96(7):2520-2527.

28. Li J, Van Der Wal DE, Zhu G, et al. Desialylation is a mechanism of Fc-independent platelet clearance and a therapeutic target in immune thrombocytopenia. Nat Commun. 2015;6:7737.

29. Chan H, Moore JC, Finch CN, Warkentin TE, Kelton JG. The IgG subclasses of platelet-associated autoantibodies directed against platelet glycoproteins $\mathrm{Ilb} / \mathrm{Illa}$ in patients with idiopathic thrombocytopenic purpura. Br J Haematol. 2003;122(5):818-824.

30. Webster ML, Sayeh E, Crow M, et al. Relative efficacy of intravenous immunoglobulin $\mathrm{G}$ in ameliorating thrombocytopenia induced by antiplatelet GPIIbIlla versus GPIbalpha antibodies. Blood. 2006;108(3):943-946.

31. Go RS, Johnston KL, Bruden KC. The association between platelet autoantibody specificity and response to intravenous immunoglobulin $\mathrm{G}$ in the treatment of patients with immune thrombocytopenia. Haematologica. 2007;92(2):283-284.

32. Peng J, Ma SH, Liu J, et al. Association of autoantibody specificity and response to intravenous immunoglobulin $G$ therapy in immune thrombocytopenia: a multicenter cohort study. J Thromb Haemost. 2014;12(4):497-504.

33. Cantoni S, Carpenedo M, Nichelatti M, et al. Clinical relevance of antiplatelet antibodies and the hepatic clearance of platelets in patients with immune thrombocytopenia. Blood. 2016;128(17):2183-2185.

34. Rumjantseva V, Grewal PK, Wandall HH, et al. Dual roles for hepatic lectin receptors in the clearance of chilled platelets. Nat Med. 2009;15(11):1273-1280.

35. Zhang H, Nimmer PM, Tahir SK, et al. Bcl-2 family proteins are essential for platelet survival. Cell Death Differ. 2007;14(5):943-951.

36. Marini I, Zlamal J, Faul C, et al. Autoantibody-mediated desialylation impairs human thrombopoiesis and platelet lifespan. Haematologica. 2021;106(1):196-207.

37. Zheng SS, Perdomo JS, Leung HHL, Yan F, Chong BH. Acquired Glanzmann thrombasthenia associated with platelet desialylation. J Thromb Haemost. 2020;18(3):714-721.

38. Zheng SS, Perdomo JS, Ahmadi Z, Chong BH. Indirect detection of anti-platelet antibodies in immune thrombocytopenia. $\mathrm{Pa}-$ thology. 2021;53(6):759-762.

39. Rodeghiero F, Stasi R, Gernsheimer T, et al. Standardization of terminology, definitions and outcome criteria in immune thrombocytopenic purpura of adults and children: report from an international working group. Blood. 2009;113(11):2386-2393.

40. Provan D, Arnold DM, Bussel JB, et al. Updated international consensus report on the investigation and management of primary immune thrombocytopenia. Blood Adv. 2019;3(22):3780-3817.

41. Brighton TA, Evans S, Castaldi PA, Chesterman CN, Chong BH. Prospective evaluation of the clinical usefulness of an antigenspecific assay (MAIPA) in idiopathic thrombocytopenic purpura and other immune thrombocytopenias. Blood. 1996;88(1):194-201.

42. Liang SX, Pinkevych M, Khachigian LM, Parish CR, Davenport MP, Chong BH. Drug-induced thrombocytopenia: development of a novel NOD/SCID mouse model to evaluate clearance of circulating platelets by drug-dependent antibodies and the efficacy of IVIG. Blood. 2010;116(11):1958-1960.

43. Al-Samkari H, Rosovsky RP, Karp Leaf RS, et al. A modern reassessment of glycoprotein-specific direct platelet autoantibody testing in immune thrombocytopenia. Blood Adv. 2019;4(1):9-18. 
44. Vollenberg R, Jouni R, Norris PAA, et al. Glycoprotein V is a relevant immune target in patients with immune thrombocytopenia. Haematologica. 2019;104(6):1237-1243.

45. Porcelijn L, Schmidt DE, van der Schoot CE, Vidarsson G, de Haas M, Kapur R. Anti-glycoprotein Ib $\alpha$ autoantibodies do not impair circulating thrombopoietin levels in immune thrombocytopenia patients. Haematologica. 2020;105(4):e172-e174.

46. Yamamoto K, Kawasaki N. Chapter Eleven - Detection of WeakBinding Sugar Activity Using Membrane-Based Carbohydrates. In: Fukuda M, ed. Methods in Enzymology: Academic Press. 2010:233-240.

47. Porcelijn L, Huiskes E, Oldert G, Schipperus M, Zwaginga JJ, de Haas M. Detection of platelet autoantibodies to identify immune thrombocytopenia: state of the art. $\mathrm{Br} \mathrm{J}$ Haematol. 2018;182(3):423-426.

48. Grodzielski M, Goette NP, Glembotsky AC, et al. Multiple con- comitant mechanisms contribute to low platelet count in patients with immune thrombocytopenia. Sci Rep. 2019;9(1):2208.

49. Amini SN, Porcelijn L, Sobels A, et al. Anti-glycoprotein antibodies and sequestration pattern of indium labeled platelets in immune thrombocytopenia. Blood Adv. 2022;6(6):1797-1803

50. Vrbensky JR, Moore JE, Arnold DM, Smith JW, Kelton JG, Nazy I. The sensitivity and specificity of platelet autoantibody testing in immune thrombocytopenia: a systematic review and metaanalysis of a diagnostic test. J Thromb Haemost. 2019;17(5):787-794.

51. Arnold DM, Santoso S, Greinacher A. Platelet Immunology Scientific Subcommittee of the ISTH. Recommendations for the implementation of platelet autoantibody testing in clinical trials of immune thrombocytopenia. J Thromb Haemost. 2012;10(4):695-697. 